\title{
Promoting the creation of R\&D intentions in primary healthcare measured by a validated instrument
}

\author{
Helena Morténius ${ }^{1,2^{*}}$ and Amir Baigi ${ }^{2,3}$
}

\begin{abstract}
Background: Primary healthcare has a long and successful patient care history in Sweden. Nevertheless, a researchoriented attitude has been more or less absent in this context. In society today, access to information has significantly influenced the nature of patients' demand for up-to-date healthcare. A prerequisite for this new demand is health professionals who are interested in novel ways of thinking and view a change of work practices as necessary. One way to achieve this goal is by means of strategic communication, which is a relatively new interdisciplinary field. The aim of this study was to analyse the role of strategic communication in the creation of intentions in Research and Development (R\&D) among primary healthcare staff as measured by a validated instrument.
\end{abstract}

Methods: An intervention study on staff was performed. A 15-item questionnaire was validated and implemented. All primary healthcare staff from the southwestern Swedish province of Halland were included. In total, 846 employees (70\%) agreed to participate in the measurements. After 12 years, 352 individuals who had participated in the intervention and remained in the organisation were identified and followed up. The intervention comprised established communication channels. The measurements were performed after 7 and 12 years. A questionnaire was designed for this purpose. The questions were validated by a factor analysis, and the degree of reliability was measured with Cronbach's alpha coefficient. $x^{2}$ and Fisher's exact tests were used as statistical tests in comparisons.

Results: Factor analysis identified five pure factors (most Cronbach's alpha > 0.70). Strategic communication contributed to a significant improvement in the staff members' interest in R\&D and willingness to change in both the short $(P<0.05)$ and long $(P<0.05)$ term. The positive attitude was stable over time.

Conclusions: Strategic communication seems to be a significant tool for creating a stable positive attitude towards $R \& D$ in the primary healthcare context. The creation of a positive attitude towards a scientific approach is a relevant finding that deserves special attention in a context as complex as healthcare. Using a validated instrument seems to contribute to pure results in this case.

Keywords: Change in work practice, interest in R\&D, primary healthcare, research and development, strategic communication, validated instrument

\footnotetext{
*Correspondence: helena.mortenius@regionhalland.se

'Department of Health Care, Region Halland, Box 517, 30180 Halmstad,

Sweden

${ }^{2}$ Department of Primary Health Care, The Sahlgrenska Academy, University of

Gothenburg, Gothenburg, Sweden

Full list of author information is available at the end of the article
}

(c) The Author(s). 2019 Open Access This article is distributed under the terms of the Creative Commons Attribution 4.0 International License (http://creativecommons.org/licenses/by/4.0/), which permits unrestricted use, distribution, and reproduction in any medium, provided you give appropriate credit to the original author(s) and the source, provide a link to the Creative Commons license, and indicate if changes were made. The Creative Commons Public Domain Dedication waiver (http://creativecommons.org/publicdomain/zero/1.0/) applies to the data made available in this article, unless otherwise stated. 


\section{Background}

The healthcare context is often described as complex and as having several layers, including individuals (multiple healthcare professionals, non-clinical staff, patients) and organisations (primary healthcare infrastructure, technology, computerised information systems, delivery of treatments to patients, culture and working practices), but the concept of complexity is subjective and depends on the context [1]. The term 'complex' is frequently employed in the scientific literature to describe tasks or systems ranging from complicated to almost impossible to manage, suggesting that many different measurements would be required to capture all intuitive ideas about complexity [2]. New information and communication technologies have changed the world. Over the past two decades, Internet use has increased and, currently, almost everyone has the opportunity to be 'connected'. In current society, access to this flow of information through various digital platforms has significantly influenced patient demand for healthcare. The one-sided monologue from a doctor and nurse to a patient has fundamentally changed due to patients' ability to perform online research; the monologue has become a dialogue. The current situation requires a better understanding of how staff have adapted to patients' recent research abilities. New technological developments and the critical approach used by patients have led to the emergence of new healthcare areas and services. Patients increasingly search for medical information on the Internet before contacting care services. Users must be able to filter the rapidly expanding flow of information, particularly information that is not medically relevant. In turn, healthcare staff have become increasingly aware of the need to apply a critical mode of thinking and to closely examine the sources of evidence-based information [3, 4]. Healthcare organisations are complex and comprise many different professional categories and operational areas in addition to several managerial levels; thus, gaps frequently arise between everyday practices and theoretical ways of thinking [5]. For example, practitioners lack sufficient ability and ambition to implement evidence-based interventions $[6,7]$. This and similar situations have led to the hiring of experts to promote awareness, knowledge, skills and self-efficacy and to create motivation among the staff to adopt evidence-based interventions [8-10]. In clinical practice, complexity is considered an important factor in patient safety and quality care $[11,12]$. The existence of multiple healthcare processes in which several factors and professional categories exert varying degrees of influence on availability and practice lead to unpredictable outcomes [13]. The current situation requires healthcare professionals to keep abreast of changes in and updates to scientific development in the field. Therefore, creating awareness of research and development (R\&D) within the organisation is necessary to promote and strengthen a positive attitude towards change for the long-term benefit of patients. The use of strategic communication among primary healthcare staff is one way to achieve such a change and has been studied in the past [14-18].

However, a readiness to change is required to establish an attitude that is conducive to new thoughts and ideas. An organisation's readiness to change (ORC) is defined as "the extent to which organisational members are both psychologically and behaviourally prepared to implement change" [19]. The chances of successful implementation are greatly improved when there is preparedness for constant change, thus avoiding a waste of resources [20].

The translation of research into practice has been neglected [21]. In this respect, an ORC can serve as a facilitator of efficient knowledge translation (KT). In the healthcare context, KT is the process of transferring knowledge from where it was created to where it can be refined and used in clinical practice and patient care [22]. An organisation characterised by systematic readiness for change is prepared to assess and anticipate the consequences of such a change. An important aspect of $\mathrm{KT}$ is the identification of methods for assessing an ORC [23]. Such a method could be strategic communication, which can promote the organisation of and reduce the gap between research and practice. Strategic communication has been defined as "the purposeful use of communication by an organisation to fulfil its mission" [24].

\section{Strategic communication}

Strategic communication is a relatively new interdisciplinary field developed in the early 2000 s $[25,26]$. The main areas of application include media and communication, sociology, political science and psychology. Strategic communication is based on several theories derived from the abovementioned disciplines, e.g. the social learning theory, information process theory and diffusion of innovation theory [27-29]. Communication is optimal when the context in question is open to new ideas either prior to or during the consolidation process [30,31]. The communication targets are achieved using established communication channels targeting specific groups by processes that provide objectively measurable results [32]. Strategic communication can be used as a tool in an organisation to create new attitudes towards willingness to change [14]. In a complex context, such as healthcare organisations, a change in attitude does not occur smoothly, and significant barriers are a natural part of the process [14]. Furthermore, perseverance and a structured approach are necessary to sustain the changed staff attitudes as the acceptance process is gradual (implicit attitudes) among practitioners [33]. Strategic communication acts through different channels but in the same direction to achieve the long-term goal. Evaluation of communication efforts has historically been narrow, measuring the number of visitors 
to events or clicks on a website, yet an integrated model for evaluating strategic communication that captures inputs, activities, outputs and outcomes to impact is preferred [34]. Validated instruments exist that measure components of personal health and staff ability to change work practices in general. Specifically, there is no validated instrument to measure the staff's intention to engage with $R \& D$, meaning their knowledge and interest as well as their creation of new thinking and willingness to change working practices. Establishing such instruments with regards to content and construct validity is therefore desirable in this subject.

\section{Aim}

The aim of this study was to analyse the role of strategic communication via direct and indirect communication channels in the creation of interest in R\&D and the willingness of primary healthcare staff to change their work practices as measured by a validated instrument. The purpose was to see if the validation of instruments could give a clearer result compared to the previous studies where the impact of single questions was examined.

\section{Methods}

\section{Design and settings}

\section{Primary healthcare organisation}

The Swedish primary healthcare organisation has a long tradition of patient care. Nevertheless, the level of research orientation within the organisation is fairly low, which has created difficulties in generating a demand for research in the field [35]. Historically, research has not been prioritised in primary care, leading to a lack of interest [36, 37], which can be linked to the absence of the following two important factors: a supportive infrastructure and a facilitative research culture [38]. Thus, investigating how the combination of behavioural factors, contexts, organisations and individuals influences the willingness to change work practices among primary healthcare staff is important $[39,40]$.

\section{Primary healthcare context}

Primary healthcare constitutes the foundation of health and medical care for the population. Its areas of responsibility include medical treatment, health promotion, disease prevention, rehabilitation and nursing care [41]. In 1996, new legislation stipulating the establishment of R\&D units was introduced to enhance scientific competence and willingness to engage in research [42]. This new legislation facilitated research outside university hospitals. As a result, R\&D units were established in primary healthcare organisations in Sweden. In general, these units are financed by the public sector.

\section{Study design}

We conducted an intervention study with a 12-year follow up.

\section{Population and intervention tool}

The size of the sample was determined based on the research team members' empirical assumption that the overall influence of communication on changes in attitude over time would be approximately $40 \%$. Given an expected hypothetical effect of at least $30 \%$ (beta error $=0.20$; power $=0.80$ ) and a significance level of 0.05 , approximately 172 individuals were required in the study cohort to demonstrate a probable statistically significant improvement. A paired sample of 352 individuals, including the follow-up of the cohort, should therefore be satisfactory to draw conclusions based on the results obtained [43].

The intervention comprised all primary healthcare staff in the province of Halland in south-western Sweden; in total, 846 employees $(70 \%)$ agreed to participate in the measurements. After 12 years, all 352 individuals who had participated in the intervention and remained in the organisation were identified and followed up. Strategic communication served as a tool for creating knowledge of $R \& D$ and a springboard for generating interest, new thoughts and a willingness to change existing work practices. All communication channels that exerted direct or indirect influence on staff were included. The communication was carried out by the R\&D staff, with the communication expert as a team leader. The measurements were performed after 7 years (short term) and 12 years (long term). Questionnaires marked with a unique number were distributed to the home addresses of staff together with a cover letter and a prepaid response envelope. Participants were guaranteed confidentiality and the ethical aspects of the study were described.

\section{Intervention process}

The design comprised established communication channels and role models (Fig. 1). The strategic communication employed in the staff cohort was influenced by a theoretical framework in terms of both the design of the communication plan and the performance of the intervention [43]. First, a surrounding world analysis was performed to obtain information about the current state of R\&D and scientific resources; then, this information was used to generate the communication plan, which served as the basis of the intervention. The surrounding world analysis subsequently formed an underlying view of the current state of $R \& D$ in the organisation [44]. The results revealed a low level of $R \& D$ activity among the staff, highlighting the issue of systematic resource allocation within the activities. Subsequently, the communication plan was operationalised to reach the goal of raising the scientific competence of all employees in the primary 


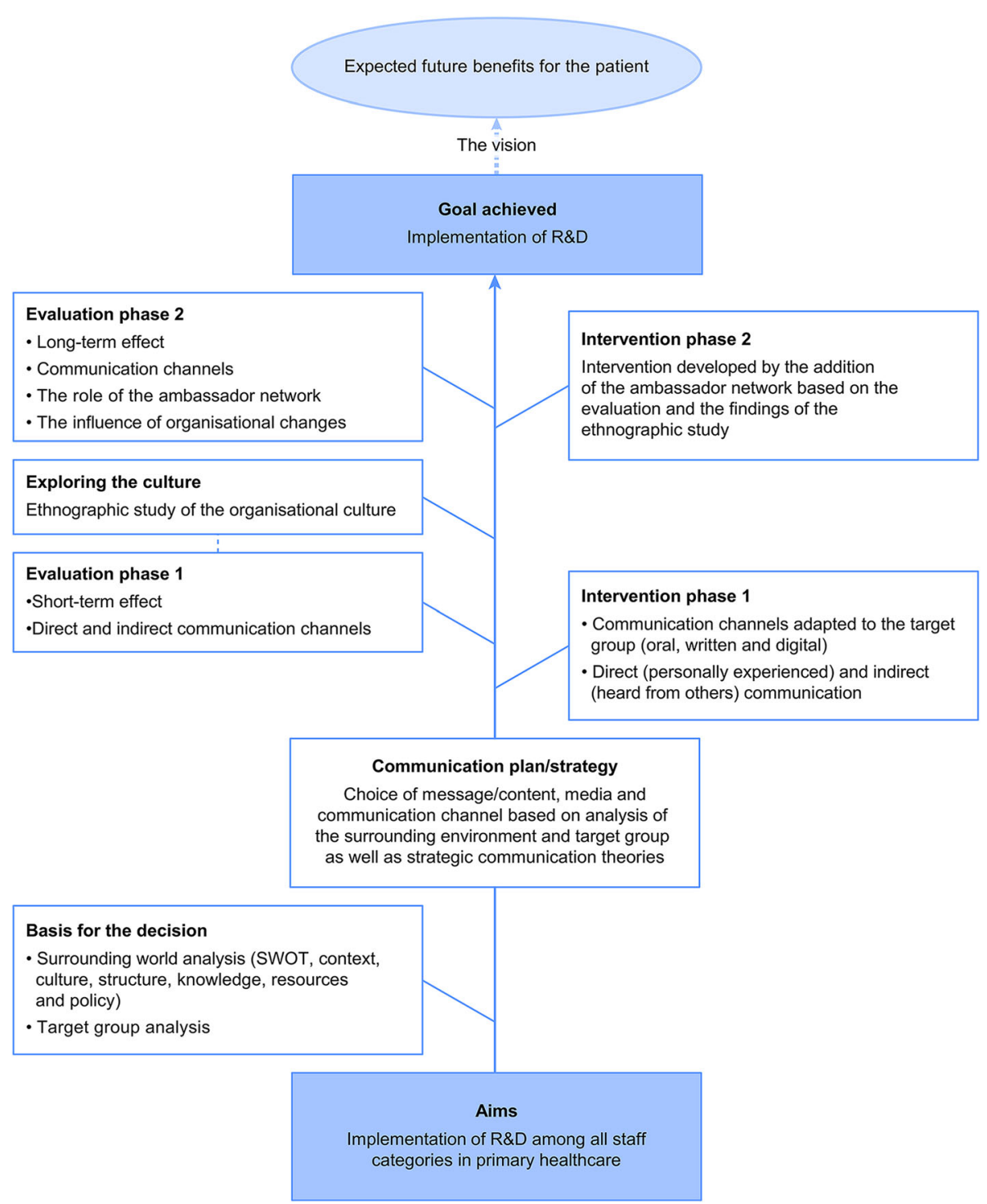

Fig. 1 The planning, intervention, follow-up and evaluation of R\&D implementation in healthcare

care area. The plan consisted of creating a preparatory scientific way of thinking with the purpose of preparing a scientific mindset for awareness and interest in $R \& D$, innovation and the willingness to change work practices.

Three established communication channels were used. Oral channels served as a 'popular-science' style method of diffusing information about research projects in the organisation. Research seminars and annual research days are examples of oral channels, while the written channels include an R\&D bulletin, research reports and popular science reports. This concept is based on communication theories involving the creation of interest, dissemination of knowledge and evaluation of results. The language used in the $R \& D$ bulletin adopted a 'popular science' style and aimed to create an interest in research, development and critical thinking. The R\&D bulletin appeared four times per year, and this regularity was important for facilitating the dissemination of information about ongoing and future R\&D activities, such as lectures and research courses, in addition to presenting reports, images and news forms, e.g. annual research conferences. The R\&D bulletin also presented and profiled those members of the organisation who were the most active in $R \& D$, thus contributing to the shaping of role models [27]. Instead of being sent to each staff member's home, copies of the R\&D bulletin were placed in common locations, such as the coffee room, to increase exposure and to encourage its contents to become a topic of conversation. Distributing the R\&D bulletin to only unit managers was deemed risky, as the managers might give the bulletin only to certain selected staff members, thus functioning as gate-keepers [29]. The digital channels were initially straightforward but gradually developed into 
active sites for the distribution of news and in-depth texts, complementing the written and oral channels by regularly providing topical information about $R \& D$ in primary healthcare. Information was disseminated through these direct channels, involving active participation/use, as well as through indirect exposure channels, including by staff members or managers involved in R\&D activities, who communicated information to their colleagues. Efforts were made to ensure that all three channels satisfied the $R \& D$ information needs of all staff members. It was expected that, in the long term, interactions among the channels' various information activities would promote the intention of staff members to engage in R\&D. As R\&D was a new concept in the organisation, the focus was on information dissemination to and acceptance of its importance by both the whole organisation and its members. The communication channels' activities were adapted to different target groups in the context of the study (Fig. 1) [29]. From the beginning, the entire communication process was established in a scientific manner to allow subsequent evaluation.

\section{Measurement instrument}

A questionnaire was employed to measure the changes in attitude during the intervention period. The questionnaire comprised 16 items pertaining to the channels' influence on the awareness of R\&D (7 direct channels; 9 indirect channels), including 15 items used for validation purposes. The item 'Participated in an R\&D course (D)' did not contribute to factor formation and was, therefore, excluded from the validation process. These items have been used as independent variables in earlier studies [14]; thus, their interaction effect was not considered (Table 1).

To determine the staff's newly created intentions through strategic communication after the start of the $R \& D$ Unit, the following questions emerged as the focus:

- Has the R\&D information in your organisation led to you...

- Developing a new way of thinking and ideas?

- Changing or intending to change your work practices?

\section{Validation process}

The process of validating the questionnaire comprised three steps, namely item construction, face and content validity, and construct validity.

\section{Step I: Item construction}

A questionnaire was constructed on the basis of a literature review and the knowledge of the research team. The team consisted of a primary healthcare communication strategist (main author), a general practitioner (primary healthcare physician), an expert in strategic communication, a healthcare expert (nurse) and a biostatistician (public health), all of whom worked together in developing and scrutinising the items. The design of the items and their relevance were discussed, and adjustments were made in a continuous process of questioning

Table 1 The 15-item instrument and distribution of the participants' responses on two occasions $(n=352)$

\begin{tabular}{|c|c|c|c|}
\hline & & \multicolumn{2}{|l|}{$n$} \\
\hline & & Occasion I & Occasion II \\
\hline \multicolumn{4}{|c|}{ Regarding one's own initiative (direct) } \\
\hline 1 & Read a popular science report & 198 & 184 \\
\hline 2 & Read the research bulletin & 270 & 252 \\
\hline 3 & Read information on the Intranet & 211 & 206 \\
\hline 4 & Read information on the Internet & 152 & 156 \\
\hline 5 & Attended a scientific seminar & 190 & 182 \\
\hline 6 & Attended a research conference & 211 & 205 \\
\hline \multicolumn{4}{|c|}{ Heard about somebody who had (indirect) } \\
\hline 7 & Described an R\&D project & 246 & 228 \\
\hline 8 & Read a popular science report & 163 & 164 \\
\hline 9 & Read the research bulletin & 172 & 182 \\
\hline 10 & Read information on the Intranet & 163 & 154 \\
\hline 11 & Read information on the Internet & 141 & 142 \\
\hline 12 & Attended a scientific seminar & 154 & 147 \\
\hline 13 & Attended an annual research conference & 166 & 159 \\
\hline 14 & Participated in an R\&D course & 174 & 161 \\
\hline 15 & Was informed about R\&D at the management level & 162 & 152 \\
\hline
\end{tabular}


the items until the group members' understanding had reached a saturation level.

\section{Step II: Face and content validity}

Once the questionnaire acquired a preliminary structure, it was distributed among the members of a pilot group. The pilot study was carried out in two steps. First, employees and contract employees $(n=20)$ were requested to read and reflect on the items and provide suggestions for improvement. The reflections were based on an exploration of the interpretation of the items and the relevance of the response alternatives and were implemented by an assessment of the readability and comprehensibility of the words and sentences. The second step was performed after the questionnaire had been amended and involved a strategic selection covering an even geographical distribution of primary healthcare areas in the county $(n=50)$ [43]. Subsequently, the staff members completed and reflected upon the questionnaire similarly to the participants of the pilot study. The revised questionnaire was further discussed in the pilot group and subjected to scrutiny by the expert group [45]; the questionnaire was then distributed to all primary healthcare staff members in the county who participated in the intervention.

\section{Step III: Construct validity}

Factor analysis To obtain the pure factors, the construct validity of the questions was measured using an explorative factor analysis [46-49]. All items were included in the factor analysis and were studied in exactly the same way on both measurement occasions, which were separated by a 5 -year interval. The population size $(n>150)$ in the study was optimal for implementing this technology, as several high loading variables were identified $[50,51]$ and the recommended ratio of participants to items, i.e. 10 cases for each item in a factor analysis, was achieved [52]. To consider the suitability of the factor analysis, Bartlett's test of sphericity was used [53]. The Kaiser-Meyer-Olkin test was performed to measure the adequacy of the sampling [54, 55]; a KaiserMeyer-Olkin value greater than 0.6 was deemed optimal for carrying out a factor analysis [50]. A principal component analysis was utilised as the factor extraction technique in which a satisfactory solution was based on the criterion that only factors with an Eigenvalue greater than or equal to 1.0 were included in further analysis $[48,50]$. Factor loadings $\geq 0.30$, including a total variance $>50 \%$, were considered meaningful $[48,56]$. The main approach to the rotation was based on the mean of the orthogonal factor solution with the Varimax rotation method. The homogeneity reliability was measured using Cronbach's alpha coefficient, and a value greater than or equal to 0.70 was considered appropriate [48].

\section{Statistical analysis Measurement of impact}

The impact of the factors on $R \& D$ interest, the new way of thinking and willingness to change work practices was measured using $X^{2}$ and Fisher's exact tests. The significance level was set at 0.05 . All tests were double-sided.

\section{Power of the study}

The sample size was based on the anticipated impact of strategic communication on interest in R\&D and willingness to change work practices. Both the short- and longterm effects were considered. As we were unable to find a similar study design in the published literature that could provide an indication of a preliminary effect size, the research team decided that the intervention should encompass all primary healthcare staff in the region.

\section{Patient and public involvement}

The study design did not include patients. The staff were informed of the importance of the survey for the primary care organisation in the long term. They did not participate in planning the study design. Furthermore, the research team formed a multidisciplinary group employed in the primary care organisation.

\section{Results}

\section{Construct validity}

A factor analysis was employed to reduce the number of items, and this process was performed identically on the two measurement occasions. The exception was item $g$, which did not form a factor and thus was excluded from the second occasion. In total, 15 items formed the following five pure factors: Seminar/conference, Bulletin/report, Intranet, Committed staff/manager and Internet. The item 'Participated in an R\&D course him/herself' did not contribute to the formation of these five factors. The total variance was $>0.50$. Similarly, the communality values were $>0.50$, except for the item 'Participated in an R\&D course (ID)', which had a somewhat lower value. There was a strong correlation among all five factors $(>0.56)$, and the values were identical on the two measurement occasions. The degree of homogeneity among the factors satisfied the requirement for an alpha coefficient $>0.70$, except for the factor 'Committed staff/manager', which had lower values on both occasions, i.e. 0.52 . The overall alpha coefficients were 0.78 and 0.79 (Table 2).

\section{Changing attitudes through R\&D communication}

The strategic communication aimed to convey the R\&D message and to create an interest in R\&D by the following direct and indirect communication activities: direct communication occurred when an individual carried out the activities, (D) and indirect communication occurred when someone else informed other individuals about the activities (ID). 
Table 2 Construct validity (factor analysis) and homogeneity (Cronbach's alpha coefficient). Utilisation of the 15-item instrument

\begin{tabular}{|c|c|c|c|c|c|c|c|c|c|c|c|c|c|c|}
\hline \multirow{2}{*}{$\begin{array}{l}\text { Items } \\
\text { Measurements I and II }\end{array}$} & \multicolumn{2}{|c|}{$\begin{array}{l}\text { Total } \\
\text { variance } \\
\%\end{array}$} & \multicolumn{2}{|c|}{ Communalities } & \multicolumn{2}{|c|}{$\begin{array}{l}\text { Seminar/ } \\
\text { conference }\end{array}$} & \multicolumn{2}{|c|}{$\begin{array}{l}\text { Bulletin/ } \\
\text { report }\end{array}$} & \multicolumn{2}{|c|}{ Intranet } & \multicolumn{2}{|c|}{$\begin{array}{l}\text { Committed } \\
\text { staff/ } \\
\text { manager }\end{array}$} & \multicolumn{2}{|c|}{ Internet } \\
\hline & I & $\|$ & 1 & $\|$ & I & $\|$ & I & $\|$ & I & ॥ & 1 & ॥ & I & $\|$ \\
\hline & 64.6 & 58.7 & & & & & & & & & & & & \\
\hline Attended a scientific seminar (ID) & & & 0.71 & 0.66 & 0.79 & 0.68 & & & & & & & & \\
\hline Attended a research conference (ID) & & & 0.75 & 0.61 & 0.78 & 0.64 & & & & & & & & \\
\hline Attended a scientific seminar (D) & & & 0.67 & 0.57 & 0.75 & 0.71 & & & & & & & & \\
\hline Attended a research conference (D) & & & 0.56 & 0.63 & 0.73 & 0.76 & & & & & & & & \\
\hline \multirow[t]{2}{*}{ Cronbach's alpha: } & & & & & 0.82 & 0.76 & & & & & & & & \\
\hline & 55.2 & 55.1 & & & & & & & & & & & & \\
\hline Read the research bulletin (D) & & & 0.67 & 0.58 & & & 0.76 & 0.66 & & & & & & \\
\hline Read a popular science report (ID) & & & 0.67 & 0.69 & & & 0.67 & 0.74 & & & & & & \\
\hline Read the research bulletin (ID) & & & 0.54 & 0.55 & & & 0.67 & 0.64 & & & & & & \\
\hline Read a popular science report (D) & & & 0.50 & 0.64 & & & 0.63 & 0.73 & & & & & & \\
\hline \multirow[t]{2}{*}{ Cronbach's alpha: } & & & & & & & 0.73 & 0.80 & & & & & & \\
\hline & 87.4 & 83.4 & & & & & & & & & & & & \\
\hline Read information on the Internet (D) & & & 0.86 & 0.70 & & & & & 0.90 & 0.82 & & & & \\
\hline Read information on the Internet (ID) & & & 0.85 & 0.74 & & & & & 0.90 & 0.81 & & & & \\
\hline \multirow[t]{2}{*}{ Cronbach's alpha: } & & & & & & & & & 0.84 & 0.80 & & & & \\
\hline & 50.8 & 51.0 & & & & & & & & & & & & \\
\hline Was informed about R\&D at the management level (ID) & & & 0.52 & 0.64 & & & & & & & 0.68 & 0.78 & & \\
\hline Participated in an R\&D course (ID) & & & 0.68 & 0.44 & & & & & & & 0.62 & 0.57 & & \\
\hline Described an R\&D project (ID) & & & 0.63 & 0.51 & & & & & & & 0.61 & 0.61 & & \\
\hline \multirow[t]{2}{*}{ Cronbach's alpha: } & & & & & & & & & & & 0.52 & 0.52 & & \\
\hline & 84.1 & 77.8 & & & & & & & & & & & & \\
\hline Read information on the Intranet (D) & & & 0.79 & 0.76 & & & & & & & & & 0.87 & 0.85 \\
\hline Read information on the Intranet (ID) & & & 0.78 & 0.68 & & & & & & & & & 0.86 & 0.67 \\
\hline Cronbach's alpha: & & & & & & & & & & & & & 0.81 & 0.71 \\
\hline $\begin{array}{l}\text { Cronbach's alpha (overall): Measurement I: } 0.78 \\
\text { Measurement II: } 0.79\end{array}$ & & & & & & & & & & & & & & \\
\hline
\end{tabular}

$D$ direct communication, $I D$ indirect communication

\section{Seminars and conferences}

Active participation in $R \& D$ seminars and annual R\&D conferences, followed by receiving information through a third party (managers and/or colleagues), were found to have significant influences on R\&D interest in both the short and long term $(P<$ 0.05). Seminars and conferences were strongly associated with staff members' new ways of thinking and willingness to change work practices in both the short and long term $(P<0.05)$.

\section{Committed staff/managers}

General information about R\&D from management, followed by specific information from those who participated in $R \& D$ education or an R\&D project, also contributed to interest in $\mathrm{R} \& \mathrm{D}$ in the short and long term $(P<0.05)$. Similar to seminars and conferences, a strong association was found between a new way of thinking and willingness to change work practices in the short and long term $(P<0.05)$.

\section{$R \& D$ bulletin/reports}

The two most frequently employed communication channels, i.e. the R\&D bulletin and popular science reports (D/ID), were the greatest contributors to creating $R \& D$ interest in the short and long term. These channels of communication also demonstrated a significant long-term association with a new way of thinking and willingness to change work practices $(P<0.05)$.

\section{Websites}

The digital communication activities demonstrated a partially positive influence on the staff members' $R \& D$ interest in the long term $(P<0.05)$ (Table 3$)$. 
Table 3 Association between the communication channels and the creation of R\&D intentions among healthcare staff

\begin{tabular}{|c|c|c|c|c|c|c|c|c|c|c|}
\hline & \multicolumn{2}{|c|}{ Seminar/conference } & \multicolumn{2}{|c|}{ Committed staff/manager } & \multicolumn{2}{|c|}{ Bulletin/report } & \multicolumn{2}{|l|}{ Internet } & \multicolumn{2}{|l|}{ Intranet } \\
\hline & $\mathrm{n}_{1} / \mathrm{N}_{1}(\%)$ & $P$ & $\mathrm{n}_{1} / \mathrm{N}_{1}(\%)$ & $P$ & $\mathrm{n}_{1} / \mathrm{N}_{1}(\%)$ & $P$ & $\mathrm{n}_{1} / \mathrm{N}_{1}(\%)$ & $P$ & $\mathrm{n}_{1} / \mathrm{N}_{1}(\%)$ & $P$ \\
\hline \multicolumn{11}{|l|}{ Measurement I: } \\
\hline$R \& D$ interest & $154 / 240(64)$ & $<0.001$ & 191/227(84) & $<0.001$ & 267/296(90) & $<0.001$ & 13/159(8) & NS & 116/218(53) & NS \\
\hline New way of thinking & 109/140(78) & $<0.001$ & $129 / 197(65)$ & $<0.001$ & 143/228 (63) & NS & 4/11 (36) & NS & $60 / 98(61)$ & NS \\
\hline \multirow[t]{2}{*}{ Willingness to change } & $48 / 65(74)$ & $<0.001$ & 64/72 (89) & $<0.023$ & 66/74 (89) & NS & 3/46 (7) & NS & 28/59 (48) & NS \\
\hline & $\mathrm{n}_{2} / \mathrm{N}_{2}(\%)$ & $P$ & $\mathrm{n}_{2} / \mathrm{N}_{2}(\%)$ & $P$ & $\mathrm{n}_{2} / \mathrm{N}_{2}(\%)$ & $P$ & $\mathrm{n}_{2} / \mathrm{N}_{2}(\%)$ & $P$ & $\mathrm{n}_{2} / \mathrm{N}_{2}(\%)$ & $P$ \\
\hline \multicolumn{11}{|l|}{ Measurement II: } \\
\hline R\&D interest & $161 / 229(70)$ & $<0.001$ & 210/248 (85) & $<0.001$ & 241/279 (86) & $<0.001$ & 29/160 (18) & NS & $132 / 215(61)$ & 0.001 \\
\hline New way of thinking & 111/144 (76) & $<0.001$ & 129/143 (69) & $<0.001$ & 150/166 (90) & 0.002 & 15/91 (17) & NS & $77 / 125(62)$ & NS \\
\hline Willingness to change & $50 / 69(73)$ & $<0.021$ & $66 / 73(90)$ & 0.008 & 67/75 (89) & 0.049 & $8 / 54(15)$ & NS & $39 / 68(57)$ & NS \\
\hline
\end{tabular}

$\mathrm{N}_{1}$ : Participated in the intervention and replied to the questionnaire

$\mathrm{N}_{2}$ : Participated in the intervention, remained in the organisation and replied to the questionnaire

$\mathrm{n}_{1}$ : Staff who changed the attitudes in the measurement I

$\mathrm{n}_{2}$ : Staff who changed/retained the attitudes in the measurement II

$X^{2}$ and Fisher's exact tests were used

NS not statistically significant

\section{Discussion}

\section{Summary}

Strategic communication contributed to a significant improvement in $R \& D$ interest and was largely associated with new ways of thinking and willingness to change work practices among primary healthcare staff members. The positive attitude was stable over time. The validation of the instrument provided a new perspective compared to that in previous studies as the role of communication in the intervention process was highly strengthened.

\section{Method issues \\ Study design}

In conducting a prospective study, baseline information is an important methodological factor. The only document available was a background report that established that no R\&D culture existed within Region Halland primary healthcare [44]. Therefore, this report was complemented by the researcher's experience based on many years of employment in this context. As baseline data were lacking, the questionnaire items were constructed, and the follow-up questions were designed to allow the participants to state whether their intention to engage in R\&D had been directly influenced by the strategic communication. The intervention included all primary healthcare staff in Region Halland. No controls were recruited due to the disparity among existing national R\&D units and the lack of uniformity of information provision in these organisations. Furthermore, the selection of controls would not meet the inclusion criteria $[57,58]$. Since the study utilised a prospective 12 -year design, following up on the long-term influence of the communication was feasible, thus providing a good overview of its impact. The intervention study comprised all professional categories, which was significant since this is an important factor in the creation of a culture across the whole healthcare chain characterised by the intention to engage in $R \& D$ [43].

\section{Validation of the instrument}

A validated questionnaire is preferable for research purposes [57]. As no such validated questionnaire could be found, our self-designed questionnaire underwent a validation process. The items pertaining to the communication channels were validated before and during the follow-up (occasion I) and during the final evaluation (occasion II), yielding identical factors. This finding should be considered a satisfactory validation of the items' categorical scale. The validation would have been more straightforward if the questions had a continuous distribution since factor analysis is based on average estimation. The number of validated instruments within the communication and implementation science field is limited. More specifically, there are few validated items regarding the role of communication channels in changing attitudes. By applying a four-phase process, our research team constructed, operationalised, implemented and validated 15 items that could be combined to measure five different aspects of communication activities. The items measuring the staff members' direct participation and indirect exposure to the communication channels covered the oral, written and digital channels and their influence on changes in attitudes in the long and short term. In previous studies, the associations of these 15 items with related items were not investigated; thus, their interaction was not considered [14] and any synergy effects within the domains could not be observed. The design of the items was improved by discussions and reflections among the interdisciplinary interprofessional research group [43] and considering the views of the pilot group 
members about how to formulate the basic pedagogical structure of the instrument in a logical way. The resulting adjustments contributed to a relatively high factor correlation within each domain with good to excellent communalities with a relatively good value for Cronbach's alpha [48]. However, the alpha value of the domain 'Committed staff/manager' was somewhat lower, which to some degree can be explained by the small number of items in this domain. This type of analysis is especially suitable for items with a rating scale $[46,48]$. As the optimal utilisation of the test requires numerical (parametric) data, the factors were checked by Spearman's correlation, which indicated equal correlations between the items.

\section{General principle}

It is widely recognised that evaluations of a self-constructed instrument likely contribute to a conflict of interest rather than describe the reality of the study context [59]. Nevertheless, this concern can serve as motivation to maintain an objective stance in planning, implementing and analysing a study. The same principle applies to the researchers' association with the R\&D unit. However, such challenges were reduced due to the interdisciplinary composition of the team and the fact that its members are practitioners in the areas of medicine, biostatistics, nursing and strategic communication.

\section{Discussion of the results}

The individual impact of the communication activities on attitude towards R\&D and R\&D intention has been previously investigated [43], whereas their interaction within a group (internal synergy) has not been considered. A factor analysis was employed to elucidate the covariation between the direct and indirect channels and the impact on the change in the staff members' attitudes. This approach is consistent with the current interpretation of the interaction between direct and indirect channels and the way in which they are generally used in social media, where the views of significant others are prioritised over those of authorities, researchers and other external actors. Thus, communication in the organisation was provided by opinion leaders and role models who, in turn, conveyed the R\&D messages to their colleagues. An innovation process requires time, as some staff members assimilate the innovation less quickly than others [30]. Therefore, the primary aim of strategic communication is to first create an interest in research towards a new way of thinking that would eventually result in the willingness to change work practices in the organisation [14]. As this concept is relatively new to the context [60], great emphasis was placed on diffusing knowledge and gaining acceptance of R\&D. An advantage of this strategy is that it contributed to $R \& D$ receiving increasing attention, curiosity being stimulated and R\&D becoming a topic of discussion [32, 61], potentially explaining why the staff members started to attend scientific seminars and research conferences. As long-term behavioural change is, in most cases, a timeconsuming process [5], it is especially important to be able to establish a continued high level of R\&D intention on a longitudinal basis [16], which was also consistent with the primary aim of the intervention. By adapting the message to the target group and using the language of popular science, larger groups of staff were reached. Furthermore, it is reasonable to assume that the pedagogical platform contributed to an environment that was easy to understand and less formal, paving the way for new thinking and willingness to change. Other contributory factors were the synergistic effects among the various communication activities and the pedagogical platform, followed by the long-term design [16]. An advantage of long-term ambition is that it creates stability in attitudes towards change, thereby paving the way for an organisational culture that is open to change [62]. However, during a long-term intervention, hidden confounders may act as a hindrance and exert a negative impact on the outcome. Research has demonstrated that the longer a person has been employed in the same workplace, the lower their willingness to utilise research findings [63]. In the present context, a potential confounder was the organisational culture [64]. This hypothesis is consistent with Morténius et al. [16], who reported a negative correlation between length of employment and willingness to change work practices. Nevertheless, the activities of the strategic communication channels contributed to a shift in paradigm within Region Halland, where an interest in R\&D and a willingness to change were observed among all staff members. This outcome is consistent with one of the great challenges in healthcare highlighted by WHO, namely, bridging the research-practice gap [65]. In view of the low implementation level of research results within healthcare, it is vital to create R\&D intentions and willingness to change [66], despite access to established platforms such as the i-PARIHS framework [67]. Due to the complexity of the healthcare organisation and varying knowledge levels, a change in staff members' attitudes towards R\&D could promote greater equality in a longer perspective in terms of readiness to change, first by influencing the organisational environment in a positive way, and second as a contributory factor in the creation of ORC.

\section{Main issues}

A scientific mode of thinking and intention to implement research results in healthcare are necessary. In the current information society, patients place increased demands on healthcare staff to be up-to-date on the most recent research, requiring encounters with patients to be characterised by a scientific stance. A long-term investment in research and innovation is essential for meeting future challenges in healthcare. However, in the practical context, 
research and innovation should occur in cooperation with different actors such as industry, pharmaceutical companies and universities [68]. Thus, the implementation strategy in a complex system, such as healthcare, must be adapted to the target group's level of knowledge. Several established frameworks, such as Cynefin [69] and i-PARIHS [67], are based on similar concepts. Strategic thinking is an important factor that includes many different aspects, such as knowledge about the organisational structure, readiness to change, climate, culture and the acceptance levels of different target groups. Therefore, it is essential to assume a long-term view of willingness to change, which is the basis of a shift in paradigm. However, the complexity requires an analytical approach and the ability to interpret several interactive dimensions in the organisation. Gaining acceptance of new thinking and willingness to change is an intricate process in a complex organisation and can easily be jeopardised by simple solutions, resulting in chaos in the system [69]. In the i-PARIHS framework, emphasis is placed on the use of facilitators with different levels of experience (novice, experienced and expert) [67], which is an aspect that should be further developed in healthcare. During the process of the implementation of a strategy to change attitudes, R\&D organisations should be considered natural bridge builders, i.e. experts, due to their 'strong links with both academic institutions and healthcare organisations', in addition to their knowledge about building networks in a specific context $[43,67]$. However, the involvement of facilitators should be carefully structured to ensure that the theoretical background and practical implementations are combined in an optimal way [70].

\section{Operative role of communication}

From a wider perspective, it is likely that the synergistic effect of the communication channels will change. The new wave of multivariation in communication gradually erases traditional boundaries. For example, social media facilitates interactions, dialogues, instant feedback and opportunities to obtain a quick overview of the surrounding world. Thus, an organisation can create new, converging forms of content and utilisation. Despite the strength of strategic communication that can be adapted to the context and communication requirements of different target groups, the new wave of communication via social media places demands on its design and content to provide an optimal effect, which may lead healthcare organisations to considerably revise their communication channels in the near future, thus contributing to additional ways of communication and enhancing the importance of the message rather than the choice of channel. This does not apply to communication through traditional or social media but concerns the choice of the most suitable medium that matches the aim of the message [71]. For the optimal utilisation of strategic communication in each unique organisation, a communication strategist has to be an integral part of the context. This person should be an expert who ensures that the practical adaptation targets relevant target groups in the organisation by applying a theoretical approach [43, 72].

Furthermore, this study provides a valuable evaluation of an instrument to assess the implementation of changing attitudes in a primary healthcare organisation. The study draws attention to contextual and staff aspects for future innovative planning in the healthcare sector and, as a consequence, for patient benefit in the long term. The creation of an organisational culture with a willingness to change work practices is also valuable for implementing new guidelines and research findings in the organisation. Furthermore, the study design and methodology can be used for educational purposes in the future.

\section{Conclusions}

Strategic communication seems to be an important tool for changing attitudes in the primary healthcare context in both the short and long term. Our finding that a positive attitude towards $R \& D$ was created in a complex context, such as healthcare, and could be measured by a validated instrument merits special attention, particularly in view of the patient perspective.

\section{Abbreviations}

$K T$ : knowledge translation; ORC: organisation's readiness to change; R\&D: research and development

\section{Acknowledgements}

This work was supported by the Department of Research \& Development, Region Halland, Sweden. The authors are grateful to the cohort team for their valuable support during the study process.

\section{Authors' contributions}

HM contributed to the planning, design and analysis of the study. AB supported the study by performing the statistical calculations and providing a scientific approach. HM and AB wrote the manuscript. HM submitted the manuscript. Both authors have read and approved the final version.

\section{Authors' information}

Helena Morténius, Healthcare strategist and scientific expert in strategic communication and implementation, MD, PhD.

Amir Baigi, Epidemiologist, MD, PhD. Associate professor.

\section{Funding}

This research received no specific grants from any funding agency in the public, commercial or not-for-profit sectors. Open access funding provided by University of Gothenburg.

\section{Availability of data and materials}

Data are available upon reasonable request from the corresponding author.

\section{Ethics approval and consent to participate}

The study conformed to the principles outlined in the Declaration of Helsinki and was approved by the Regional Ethics Committee, Lund, Sweden (2009/ 7). All participants were invited to complete the questionnaire, were informed about the voluntary nature of their participation and were guaranteed confidentiality.

Consent for publication

None declared. 


\section{Competing interests}

The authors declare that they have no competing interests.

\section{Author details}

'Department of Health Care, Region Halland, Box 517, 30180 Halmstad, Sweden. ${ }^{2}$ Department of Primary Health Care, The Sahlgrenska Academy, University of Gothenburg, Gothenburg, Sweden. ${ }^{3}$ Department of Research and Development, Region Halland, Halmstad, Sweden.

\section{Received: 23 April 2019 Accepted: 27 November 2019}

Published online: 30 December 2019

\section{References}

1. Mainzer K. Thinking in Complexity. New York: SpringerVerlag; 1997.

2. Gell-Mann M. What is complexity? Remarks on simplicity and complexity by the Nobel Prize-winning author of the Quark and the Jaguar. Complexity. 1995;1:16-9.

3. Glasgow RE, Emmons KM. How can we increase translation of research into practice? Types of evidence needed. Annu Rev Public Health. 2007;28:413-33.

4. Munn Z, Lockwood C, Moola S. The development and use of evidence summaries for point of care information systems: a streamlined rapid review approach. Worldviews Evid-Based Nurs. 2015:12:131-8.

5. Helfrich CD, Blevins D, Smith JL, Kelly PA, Hogan TP, Hagedorn H, et al. Predicting implementation from organizational readiness for change: a study protocol. Implement Sci. 2011;6:76.

6. Dodson EA, Baker EA, Brownson RC. Use of evidence-based interventions in state health departments: a qualitative assessment of barriers and solutions. J Public Health Manag Pract. 2010;16:E9-15.

7. Steele CB, Rose JM, Chovnick G, Townsend JS, Stockmyer CK, Fonseka J, et al. Use of evidence-based practices and resources among comprehensive cancer control programs. J Public Health Manag Pract. 2015;21:441-8.

8. Collins CB, Sapiano TN. Lessons learned from dissemination of evidencebased interventions for HIV prevention. Am J Prev Med. 2016:51:S140-7.

9. Rabin BA, Glasgow RE, Kerner JF, Klump MP, Brownson RC. Dissemination and implementation research on community-based cancer prevention: a systematic review. Am J Prev Med. 2010;38:443-56.

10. Flaspohler P, Duffy J, Wandersman A, Stillman L, Maras MA. Unpacking prevention capacity: an intersection of research-to-practice models and community-centered models. Am J Community Psychol. 2008;41:182-96.

11. Patel VL, Cohen T. New perspectives on error in critical care. Curr Opin Crit Care. 2008;14:456-9.

12. Plsek PE, Greenhalgh T. Complexity science: the challenge of complexity in health care. BMJ. 2001;323:625-8.

13. Litaker D, Tomolo A, Liberatore V, Stange KC, Aron D. Using complexity theory to build interventions that improve health care delivery in primary care. J Gen Intern Med. 2006;21(Suppl 2):S30-4.

14. Mortenius H, Marklund B, Palm L, Bjorkelund C, Baigi A. Implementation of innovative attitudes and behaviour in primary health care by means of strategic communication: a 7-year follow-up. J Eval Clin Pract. 2012;18:659-65.

15. Mortenius H, Marklund B, Palm L, Fridlund B, Baigi A. The utilization of knowledge of and interest in research and development among primary care staff by means of strategic communication - a staff cohort study. J Eval Clin Pract. 2012;18:768-75.

16. Mortenius $H$, Fridlund B, Marklund B, Palm L, Baigi A. Utilisation of strategic communication to create willingness to change work practices among primary care staff: a long-term follow-up study. Prim Health Care Res Dev. 2012;13:130-41.

17. Mortenius $\mathrm{H}$. Creating an interest in research and development as a means of reducing the gap between theory and practice in primary care: an interventional study based on strategic communication. Int J Environ Res Public Health. 2014;11:8689-708.

18. Mortenius $\mathrm{H}$, Hildingh $\mathrm{C}$, Fridlund B. Strategic communication intervention to stimulate interest in research and evidence-based practice: a 12-year follow-up study with registered nurses. Worldviews Evid-Based Nurs. 2016;13:42-9.

19. Holt DT, Helfrich CD, Hall CG, Weiner BJ. Are you ready? How health professionals can comprehensively conceptualize readiness for change. J Gen Intern Med. 2010;25(Suppl 1):50-5.

20. Jennett PA, Gagnon MP, Brandstadt HK. Preparing for success: readiness models for rural telehealth. J Postgrad Med. 2005;51:279-85.

21. Gagnon MP, Attieh R, Ghandour EK, Legare F, Ouimet M, Estabrooks CA, et al. A systematic review of instruments to assess organizational readiness for knowledge translation in health care. PLoS One. 2014;9:e114338.
22. McKibbon KA, Lokker C, Wilczynski NL, Ciliska D, Dobbins M, Davis DA, et al. A cross-sectional study of the number and frequency of terms used to refer to knowledge translation in a body of health literature in 2006: a tower of Babel? Implement Sci. 2010;5:16.

23. Greenhalgh T, Robert G, Bate P, Macfarlane F, Kyriakidou O. Diffusion of Innovations in Health Service Organisations: A Systematic Literature Review. Malden, MA, London: Blackwell Publishing; 2005.

24. Hallahan K, Holtzhausen D, van Ruler B, Verčič D, Sriramesh K. Defining strategic communication. Int J Strateg Commun. 2007;1:3-35.

25. Falkheimer J, Heide M. Strategic Communication: An Introduction. Oxon: Routledge; 2018.

26. Werder KP, Nothhaft H, Verčič D, Zerfass A. Strategic communication as an emerging interdisciplinary paradigm. Int J Strateg Commun. 2018;12:333-51.

27. Bandura A, Locke EA. Negative self-efficacy and goal effects revisited. J Appl Psychol. 2003;88:87-99.

28. McGuire WJ. Personality and attitude change: an information-processing theory. In: Greenwald AG, Brock TC, Ostrom TM, editors. Psychological Foundations of Attitudes. New York: Academic Press; 1968. p. 171-96.

29. Rogers EM. Diffusion of Innovations. 5th ed. New York: Free Press; 2003.

30. Rogers EM. Lessons for guidelines from the diffusion of innovations. Jt Comm J Qual Improv. 1995:21:324-8.

31. Kitson AL, Rycroft-Malone J, Harvey G, McCormack B, Seers K, Titchen A. Evaluating the successful implementation of evidence into practice using the PARiHS framework: theoretical and practical challenges. Implement Sci. 2008;3:1.

32. Windahl S, Signitzer B, Olson JT. Using Communication Theory: An Introduction to Planned Communication. 2nd ed. London: Sage Publications Ltd.; 2008.

33. Rydell RJ, McConnell AR. Understanding implicit and explicit attitude change: a systems of reasoning analysis. J Pers Soc Psychol. 2006;91:995-1008.

34. Macnamara J. A review of new evaluation models for strategic communication: progress and gaps. Int J Strateg Commun. 2018;12:180-95.

35. Gensichen J, Huchzermeier C, Aldenhoff JB, Gerlach FM, Hinze-Selch D. Signals for the initiation of structured diagnostic procedures for depression in primary health care. A practice-relevant evaluation of international guidelines. Z Arztl Fortbild Qualitatssich. 2005;99:57-63.

36. Funk SG, Champagne MT, Wiese RA, Tornquist EM. Barriers to using research findings in practice: the clinician's perspective. Appl Nurs Res. 1991;4:90-5.

37. Whitford DL, Walker C, Jelley D, Clarke CL, Watson B. Developing R\&D capacity in a primary care trust: use of the R\&D culture index. Prim Health Care Res Dev. 2005:6:17-23.

38. Jowett SM, Macleod J, Wilson S, Hobbs FD. Research in primary care: extent of involvement and perceived determinants among practitioners from one English region. Br J Gen Pract. 2000;50:387-9.

39. Godin G, Belanger-Gravel A, Eccles M, Grimshaw J. Healthcare professionals' intentions and behaviours: a systematic review of studies based on social cognitive theories. Implement Sci. 2008;3:36

40. Foy $R$, Eccles $M$, Grimshaw J. Why does primary care need more implementation research? Fam Pract. 2001;18:353-5.

41. World Health Organization. Declaration of Alma-Ata. In: Adopted at the International Conference on Primary Health Care. Geneva: WHO; 1978. p. 1-78.

42. Regeringskansliet (Goverment offices of Sweden). Hälso- och sjukvårdslagen 26b§ 1996:1289 (The law of the healtcare system in Sweden). Stockholm: Regeringskansliet (Goverment Offices of Sweden); 1996.

43. Mortenius H. Implementation of Research and Development in Primary Care by Means of Strategic Communication. Sweden: Department of Public Health and Community Medicine, Institute of Medicine, Sahlgrenska Academy at University of Gothenburg; 2012.

44. Ahlenius D. FoU, Forskning och utveckling. (Research and Development). Halmstad: Landstinget Halland (County Council of Halland); 1995.

45. Kuusela H, Paul P. A comparison of concurrent and retrospective verbal protocol analysis. Am J Psychol. 2000;113:387-404.

46. Kim J, Mueller CW. Factor Analysis: Statistical Methods and Practical Issues. Newbury Park, London, New Delhi: Sage Publications; 1978

47. Kim J, Mueller CW. Introduction to Factor Analysis - What it is and How to do it. Newbury Park, London: Sage Publications; 1978.

48. Rattray J, Jones MC. Essential elements of questionnaire design and development. J Clin Nurs. 2007;16:234-43.

49. Thurstone LL. Multiple-Factor Analysis: A Development and Expansion of the Vectors of Mindbreak. Chicago: The University of Chicago Press; 1947.

50. Tabachnick BG, Fidell LS. Using Multivariate Statistics. 5th ed. Boston: Pearson Education; 2007 
51. Stevens J. Applied Multivariate Statistics for the Social Sciences. 3rd ed. Mahwah: Lawrence Erlbaum Associates; 1996.

52. Nunnally JC. Psychometric Theory. 2nd ed. New York: McGraw-Hill; 1978.

53. Bartlett MS. A note on the multiplying factors for various chi square approximations. J R Stat Soc. 1954;16:296-8.

54. Kaiser HF. A second generation little jiffy. Psychometrika. 1970;35:401-15.

55. Kaiser HF. An index of factorial simplicity. Psychometrika. 1974;39:31-6.

56. Polit DF, Beck CT. Nursing Research: Generating and Assessing Evidence for Nursing Practice. Philadelphia, London: Wolters Kluwer Health/lippincott Williams \& Wilkins; 2008.

57. Porta MS, Greenland S, Last JM. A Dictionary of Epidemiology. Oxford: Oxford University Press; 2008.

58. Rothman KJ. Epidemiology: An Introduction. Oxford: Oxford University Press; 2002.

59. Heide M, Johansson C, Simonsson C. Kommunikation \& Organisation (Communication \& Organisation). Malmö: Liber; 2005.

60. Ovhed I, van Royen P, Hakansson A. What is the future of primary care research? Probably fairly bright, if we may believe the historical development. Scand J Prim Health Care. 2005;23:248-53.

61. Palm L. Kommunikationsplanering. En handbok på vetenskaplig grund. (Communication planning. A handbook on evidence-based practice). Lund: Stundentlitteratur; 2006.

62. Drucker PF. The discipline of innovation. Harv Bus Rev. 1998;76:149-57.

63. Forsman H, Rudman A, Gustavsson P, Ehrenberg A, Wallin L. Nurses' research utilization two years after graduation--a national survey of associated individual, organizational, and educational factors. Implement Sci. 2012;7:46.

64. Mortenius H, Baigi A, Palm L, Fridlund B, Bjorkelund C, Hedberg B. Impact of the organisational culture on primary care staff members' intention to engage in research and development. J Health Organ Manag. 2015;29:234-51.

65. World Health Organization. Bridging the "Know-Do" Gap Meeting on Knowledge Translation in Global Health. Geneva: WHO; 2006.

66. Stewart M, Reid G, Brown JB, Burge F, Dicenso A, Watt S, et al. Development and implementation of training for interdisciplinary research in primary health care. Acad Med. 2010:85:974-9.

67. Kitson AL, Harvey G. Methods to succeed in effective knowledge translation in clinical practice. J Nurs Scholarsh. 2016:48:294-302

68. Vinnova (Swedish Govermental Agancy for Innovation Systems). Forskning—-till vilken nytta? (Research—What's the Use?). Stockholm: Samhällsförlaget; 2012

69. Snowden DJ, Boone ME. A leader's framework for decision making. A leader's framework for decision making. Harv Bus Rev. 2007;85:68-76 149.

70. Berta W, Cranley L, Dearing JW, Dogherty EJ, Squires JE, Estabrooks CA. Why (we think) facilitation works: insights from organizational learning theory. Implement Sci. 2015;10:141.

71. Falkheimer J, Heide M. Reflexiv kommunikation: nya tankar för strategiska kommunikatörer [Reflexive Communication]. Malmö: Liber; 2003.

72. Brownson RC, Jacobs JA, Tabak RG, Hoehner CM, Stamatakis KA. Designing for dissemination among public health researchers: findings from a national survey in the United States. Am J Public Health. 2013;103:1693-9.

\section{Publisher's Note}

Springer Nature remains neutral with regard to jurisdictional claims in published maps and institutional affiliations.

Ready to submit your research? Choose BMC and benefit from:

- fast, convenient online submission

- thorough peer review by experienced researchers in your field

- rapid publication on acceptance

- support for research data, including large and complex data types

- gold Open Access which fosters wider collaboration and increased citations

- maximum visibility for your research: over $100 \mathrm{M}$ website views per year

At $\mathrm{BMC}$, research is always in progress.

Learn more biomedcentral.com/submissions 